\title{
Study of adsorptive materials obtained by wet fine milling and acid activation of vermiculite
}

\author{
Agnieszka Węgrzyn $^{\mathrm{a}, *}$, Wojciech Stawiński ${ }^{\mathrm{b}}{ }^{*}$, Olga Freitas ${ }^{\mathrm{b}}$, Kamila Komędera ${ }^{\mathrm{c}}$, \\ Artur Błachowski ${ }^{\mathrm{c}}$, Łukasz Jęczmionek ${ }^{\mathrm{d}}$, Tomasz Dańko ${ }^{\mathrm{a}, \mathrm{e}}$, Grzegorz Mordarski ${ }^{\mathrm{f}}$, \\ Sónia Figueiredo ${ }^{\mathrm{b}}$ \\ ${ }^{a}$ Faculty of Chemistry, Jagiellonian University, ul. Ingardena 3, 30-060 Kraków, Poland \\ b REQUIMTE, LAQV, Instituto Superior de Engenharia do Porto, Instituto Politécnico do Porto, Rua Dr. António Bernardino de Almeida 431, $4200-072$ Porto, Portugal \\ ${ }^{\mathrm{c}}$ Mössbauer Spectroscopy Laboratory, Pedagogical University, ul. Podchorażych 2, 30-084 Kraków, Poland \\ d Oil and Gas Institute - National Research Institute, ul. Lubicz 25A, 31-503 Kraków, Poland \\ e Institute of Physical Chemistry, Polish Academy of Sciences, 44/52 Kasprzaka Street, 01-224 Warsaw, Poland \\ ${ }^{\mathrm{f}}$ Jerzy Haber Institute of Catalysis and Surface Chemistry Polish Academy of Sciences, ul. Niezapominajek 8, 30-239 Kraków, Poland
}

\section{A B S T R A C T}

\begin{abstract}
Wet fine milling, as a pretreatment step to acid activation of vermiculite, was applied in order to decrease the environmental impact of the procedure commonly used to increase the mineral's adsorption capacity. Milling caused fragmentation of the material and several changes in its structure: edges of the flocks became frayed, the surface cracked, cation exchange capacity (CEC) increased, and most of the iron in oligonuclear and bulk form was removed. At the same time the specific surface area, crystallinity, chemical composition and adsorption capacity did not change significantly. Fine ground material was more susceptible to acid activation, which caused a decrease in the crystallinity and CEC, development of meso- and microporosity, an increase in the total volume of pores, in the specific surface and external surface areas. Micropores were developed faster in lower acid concentrations in the rough ground material, while the external surface area and total pores volume increased faster in the fine ground vermiculite. The latter material also had a higher CEC. Application of $0.5 \mathrm{~mol} \mathrm{~L}^{-1} \mathrm{HNO}_{3}$ to rough ground vermiculite did not change its adsorption capacity, however it changed from $55 \pm 7$ to $110 \pm 8 \mathrm{mg} \mathrm{g}^{-1}$ when the material was fine ground. The optimal treatment conditions for both materials were obtained for $1.0 \mathrm{~mol} \mathrm{~L}^{-1} \mathrm{HNO}_{3}$, however the adsorption capacity for the fine ground vermiculite increased more (i.e., from $55 \pm 7$ to $136 \pm 7 \mathrm{mg} \mathrm{g}^{-1}$ ) than for its rough ground counterpart (i.e., $52 \pm 7$ to $93 \pm 7 \mathrm{mg} \mathrm{g}^{-1}$ ). Concentrations higher than $1.0 \mathrm{~mol} \mathrm{~L}^{-1}$ resulted in deterioration of the adsorption capacities in both cases. Considering all the experimental outcomes, it can be concluded that the environmental impact of acid activation of vermiculite may be diminished by application of fine grinding of the material before the chemical activation process. Such treatment resulted in higher adsorption capacity at a given acid concentration compared to the rough ground material.
\end{abstract}

Keywords:

Milled vermiculite

Acid activation

Increased adsorption capacity

Reduced environmental impact

Wastewater treatment

\section{Introduction}

The global community is becoming increasingly aware of both the environmental presence and the real or potential environmental impact of man-made chemicals (Peake et al., 2016). Continuous contamination of the environment with diverse groups of chemical compounds and their adverse effects on both ecosystem and human health is one of the most relevant environmental issues of today (Kuzmanovic et al., 2013). Decreasing the environmental impact of wastewaters to acceptable levels has become the first and major concern of the uttermost importance and the demand on efficient, economic and environment friendly technologies of removing pollutants at affordable costs has been rising (Sevekow, 2003; Pereira and Alves, 2011). Dyes are common pollutants generated in various industries such as paper, plastics, food, cosmetics, and textile (Rozada et al., 2003; Angın et al., 2013). They are usually the first to be noticed in water bodies because of their intense color, they exhibit ecotoxicity and by interrupting light penetration in aquatic environments hinder photosynthetic activity (Forgacs et al., 2004; Bhatnagar and Jain, 2005). Adsorption is considered one of the most promising, effective and attractive approach for

\footnotetext{
* Corresponding authors.

E-mail addresses: wegrzyn@chemia.uj.edu.pl (A. Węgrzyn), Wojciech.Stawinski@graq.isep.ipp.pt (W. Stawiński), omf@isep.ipp.pt (O. Freitas), saf@isep.ipp.pt (S. Figueiredo).
} 
water treatment giving wide control over water pollution (Gupta and Ali, 2012; Teng and Low, 2012; Hadi et al., 2015). Layered materials show promising perspectives in this field to be used as adsorbents (Roy et al., 2006). Vermiculite is a clay mineral that is very abundant and much cheaper compared with other clay minerals, it is also commonly used in agricultural, industrial and environmental applications (Duman and Tunç, 2008). Due to its structural characteristics it exhibits good adsorption properties towards cationic species. Clay minerals can be subjected to various modifications in order to change their properties (Bergaya and Lagaly, 2006; Komadel and Madejova, 2006; Lagaly et al., 2006; Stawiński et al., 2017a). One of the most common modifications is acid activation. It results in an increase of porosity and specific surface area and thus formation of new adsorption centers what increases the maximum adsorption capacity (Komadel and Madejova, 2006; Steudel et al., 2009; Santos et al., 2015; Stawiński et al., 2016). Furthermore, catalytic properties, based on increased materials acidity, may be improved as well (Chmielarz et al., 2012). However, this process might be considered as unsustainable and not fulfilling the premise of Green Chemistry (Anastas and Warner, 1998) as it usually produces highly acidic waste containing metals leached during the procedure. One solution to this problem was using the waste to produce layered double hydroxides, however other ways to reduce the environmental impact to acid activation of clay minerals should be investigated.

The issue of changes in vermiculite upon grinding has been already raised by some authors. Barabaszová and Valášková (2013) characterized that material after different milling techniques, Pérez-Maqueda et al. (2004) carried our studies on ground and sonicated vermiculite, Maqueda et al. (2007, 2009) and Perez-Rodriguez et al. (2011) studied leaching of ground vermiculite. However, to the authors' best knowledge, studies on wet milling, as well as adsorption studies on such prepared materials is lacking.

The aim of this study was to examine the influence of wet milling of vermiculite on its susceptibility to acid activation in order to increase the sustainability of acid activation process, and to investigate adsorption properties on these materials.

\section{Experimental}

\subsection{Adsorbents preparation}

South African raw vermiculite (fraction $0.5-1 \mathrm{~mm}$ ) was kindly supplied by ROMICO POLSKA Sp. z o.o. Two procedures of particle size reduction were applied prior to chemical activation: a) milling in a grinder with steel blades to obtain fraction below $355 \mu \mathrm{m}$ ( $5 \mathrm{~g}$ of raw material ground for $30 \mathrm{~s}$, rough ground vermiculite (AV)), b) grinding in a planetary mill (Planetary Mono Mill Pulverisette 6, Fritsch, $27 \mathrm{~g}$ of raw materials mixed with $75 \mathrm{~mL}$ of distilled water was ground for $6 \mathrm{~h}$ at $350 \mathrm{rpm}$, fine ground vermiculite AVg). Ground sample (AVg) was filtered, washed with distilled water and dried at $50{ }^{\circ} \mathrm{C}$. Acid treatment was performed using $0.5,1$ and $2 \mathrm{~mol} \mathrm{~L}^{-1}$ solutions of $\mathrm{HNO}_{3}$ (analytical grade, Chempur). Portions of $25 \mathrm{~g}$ of each material were transferred to round-bottom flasks containing $50 \mathrm{~mL}$ of pre-heated to $98{ }^{\circ} \mathrm{C}$ acid solution and equipped with a reflux condenser, then stirred for $2 \mathrm{~h}$ keeping the temperature constant. In the next step the samples were filtered, washed with distilled water and dried at $50{ }^{\circ} \mathrm{C}$. Acid concentration used in the activation was indicated in samples' names (suffixes N0.5, N1.0, N2.0), suffix c550 indicates calcination at $550{ }^{\circ} \mathrm{C}$.

\subsection{Material characterization}

Particle size distribution was assessed using test sieves with nominal sieve opening varying from 45 to $355 \mu \mathrm{m}$. The structure of the materials was studied with X-ray powder diffractometer (Bruker, D2 Phaser) equipped with $\mathrm{CuK} \alpha$ radiation source $(\lambda=0.154184 \mathrm{~nm})$, measurement range: $2-70^{\circ} 2 \theta$, step size: $0.02^{\circ} 2 \theta$, slit width: $0.6 \mathrm{~mm}$, step scan size: $0.02^{\circ}$, counting time: $1 \mathrm{~s}$. Mössbauer spectroscopy measurements were performed in transmission mode using RENON MsAa-3 spectrometer equipped with the LND $\mathrm{Kr}$-filled proportional detector and $\mathrm{He}-\mathrm{Ne}$ laser based interferometer used to calibrate velocity scale. A single line commercial ${ }^{57} \mathrm{Co}(\mathrm{Rh})$ source kept at room temperature was applied for $14.41-\mathrm{keV}$ resonant transition in ${ }^{57} \mathrm{Fe}$. Spectra were collected for about $24 \mathrm{~h}$ for materials kept at room temperature and fitted within transmission integral approximation by means of the MOSGRAF2009 software. The coordination and aggregation of iron present in the samples was determined using UV-VIS-Diffuse Reflectance spectroscopy and measured in the range of $200-900 \mathrm{~nm}$ with a resolution of $2 \mathrm{~nm}$ 600, scan speed: $120 \mathrm{~nm} \mathrm{~min}{ }^{-1}$, band width: $2 \mathrm{~nm}$ using an Evolution 600 (Thermo Scientific) spectrophotometer. Infrared spectra of the samples were recorded using Attenuated Total Reflectance technique in the range of $525-4000 \mathrm{~cm}^{-1}$ with resolution of $2 \mathrm{~cm}^{-1}$, number of scans: 50 (Nicolet 6700 FT-IR, DTGS detector, Thermo Scientific). Second derivative methods were used in the case of ATR-FTIR and UV-Vis-DRS analyses for better detection of the peaks. The textural parameters of calcined $\left(550{ }^{\circ} \mathrm{C}, 6 \mathrm{~h}\right)$ and outgassed $\left(350{ }^{\circ} \mathrm{C}\right.$ overnight in high vacuum) samples were determined by adsorption of $\mathrm{N}_{2}$ at $-196{ }^{\circ} \mathrm{C}$ using a 3 Flex (Micromeritics) surface characterization analyzer. Cation exchange capacity was determined using the ammonium acetate method (Steudel, 2008). Chemical composition of samples was determined using X-ray fluorescence (XRF) analysis (Skayray Instrument EDX $3600 \mathrm{H}$ - Alloy Analyser). The samples' thermal decomposition was determined as the function of weight loss that occurred during the temperature increase. Samples were heated in the Setaram LabsysTM apparatus for thermogravimetric analysis at the constant heating rate of $10{ }^{\circ} \mathrm{C} \mathrm{min}^{-1}$ in the temperature range from $20^{\circ} \mathrm{C}$ to $1000{ }^{\circ} \mathrm{C}$ and in air atmosphere (gas flow of $100 \mathrm{~mL} \mathrm{~min}^{-1}$ ). The SEM/EDS analysis was performed using a High resolution (Schottky) Environmental Scanning Electron Microscope with X-Ray Microanalysis and Electron Backscattered Diffraction analysis: Quanta 400 FEG ESEM/EDAX Genesis X4M. Samples were coated with an Au/Pd thin film by sputtering, using the SPI Module Sputter Coater equipment.

\subsection{Adsorption experiments}

Adsorption experiments were conducted at room temperature, without $\mathrm{pH}$ adjustment, with a magnetic stirrer (Velp, Multistirrer 15) and a centrifuge (Sartorius, Sigma 2-16) using a cationic dye Astrazon Red FBL 200\% (AR), CI 85496-37-3, supplied by Dystar (Fig. S1, Supplementary materials). Concentration of the dye was determined using UV-Vis spectrophotometer (Thermo Scientific, Evolution 220) at $531 \mathrm{~nm}$ and the adsorption capacities were calculated using Eq. (1).

$q_{e}=\frac{\left(C_{0}-C_{e q}\right) V}{m}$

where $q_{e}$ adsorption capacity ( $\mathrm{mg} \mathrm{g}^{-1}$ ), $C_{0}$ and $C$ initial and final concentrations ( $\mathrm{mg} \mathrm{L}^{-1}$ ) respectively, $V$ volume of adsorbate $(\mathrm{mL}), m$ adsorbent mass (mg).

In the kinetic studies, $100 \mathrm{mg}$ of each material was placed in a different Erlenmeyer flask with a cap and mixed with $200 \mathrm{~mL}$ of $100 \mathrm{mg} \mathrm{L}^{-1}$ dye solution. While the flasks were constantly stirred (for $2 \mathrm{~h}$ ) samples were collected at pre-determined time intervals, immediately centrifuged ( $1 \mathrm{~min}$ at 4500 r.p.m.) and concentration of the dye in the supernatant determined.

In the equilibrium studies portions of $20 \mathrm{mg}$ of each material were placed in Erlenmeyer flasks with caps and mixed with $30 \mathrm{~mL}$ of the dye solution of concentrations varying from $30 \mathrm{mg} \mathrm{L}^{-1}$ to $200 \mathrm{mg} \mathrm{L}^{-1}$. The flasks were stirred for $2 \mathrm{~h}$, centrifuged and concentration of the dye in the supernatant determined in all samples. A blank test was performed in both studies.

\subsection{Data analysis}

Two kinetics models (i.e., pseudo 1st order (Lagergren, 1898) and 

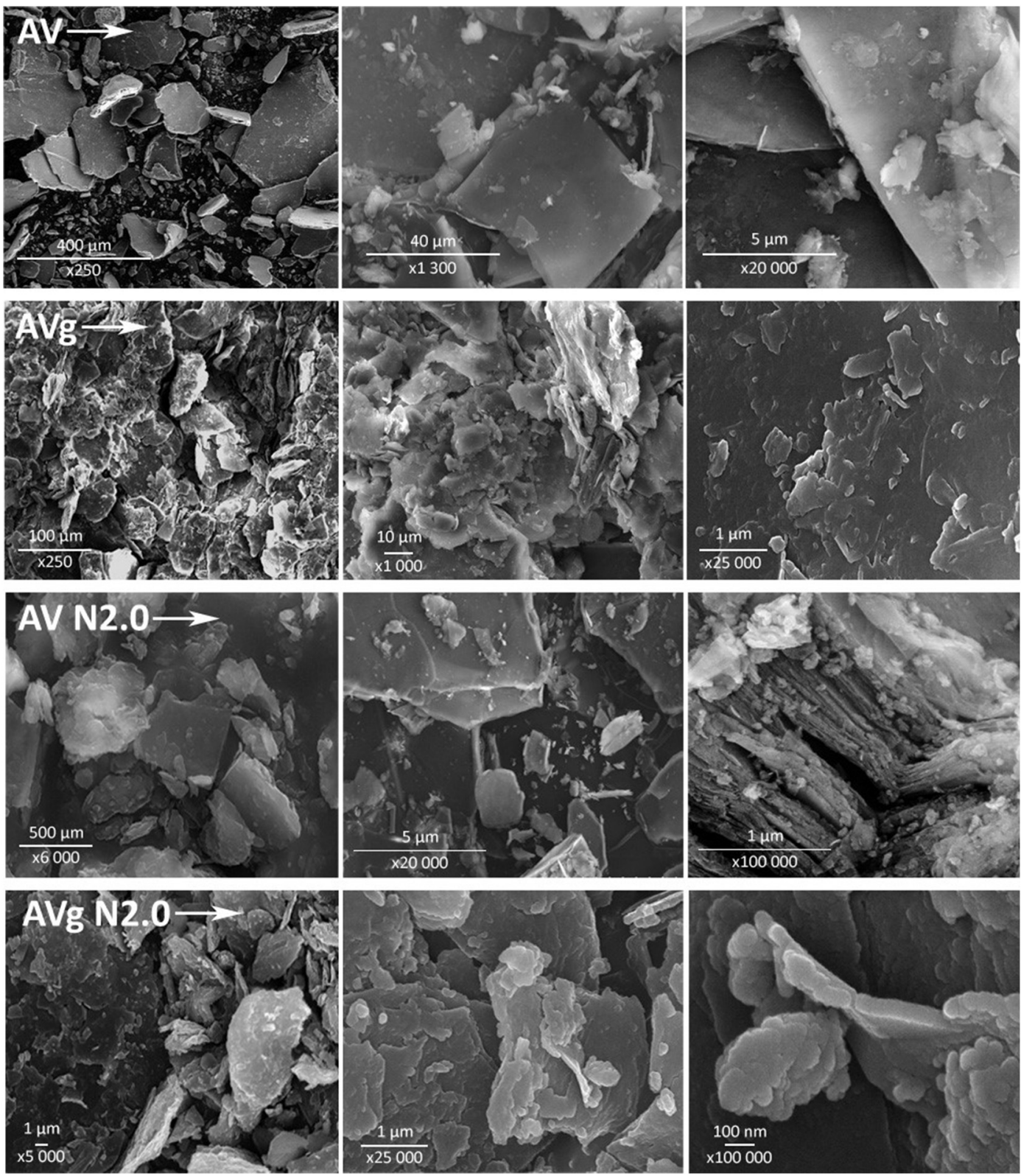

Fig. 1. SEM micrographs of mechanically and chemically modified vermiculite.

pseudo 2nd order model (Ho and McKay, 1999)) and two equilibrium models (i.e., Freundlich's (1906) and Langmuir's (1918) models) were fitted to the obtained data fitted using non-linear regression. Variances and correlation coefficients were determined and compared using F-test $(\mathrm{F})$, Akaike's Information Criterion (AIC) and Bayesian Information Criterion (BIC) tests. Models' equations are presented in the Supplementary materials.

\section{Results}

\subsection{Characterization of materials}

\subsubsection{SEM}

The images of the rough ground vermiculite (AV) showed layered morphology typical for this mineral. In the fine ground material (AVg) this structure was kept however, the surface was riddled with cracks, cleavages, and crevices. After acid treatment the micrographs showed irregular blocks with altered edges due to the selective dissolution. The fine ground material after acid activation (AVg N2.0) had frayed and corrugated edges and heterogeneous particle size distribution. Also in this case several cracks were visible on the surface of the bigger particles Fig. 1).

\subsubsection{Chemical composition and CEC}

The cation exchange capacity (CEC) of the fine ground untreated material $(\mathrm{AVg})$ was significantly higher comparing to its rough ground counterpart (AV) and this trend was kept in the acid activated samples. The cracks and cleavages in the surface of the material formed upon fine grinding may facilitate exchange of the $\mathrm{NH}_{4}{ }^{+}$cations and their penetration between the layers. Grinding may also create specific scrolled edges that upon saturation with $\mathrm{NH}_{4}{ }^{+}$tend to unscroll exposing additional adsorption sites (Raman and Mortland, 1966) thus the CEC was higher. Acid leaching causes lowering of the layer charge (Schoonheydt and Johnston, 2006) thus the CEC was diminished in the materials subjected to the treatment (Table 1).

Both starting materials before acid activation had similar chemical composition. The rough ground sample treated with $0.5 \mathrm{~mol} \mathrm{~L}^{-1}$ acid did not significantly differ from the starting material, however its fine 
Table 1

Chemical composition and cation exchange capacity (CEC) of the adsorbents.

\begin{tabular}{llllll}
\hline \multirow{2}{*}{ Sample } & CEC $\left(\mathrm{cmol}(+) \mathrm{kg}^{-1}\right)$ & \multicolumn{4}{l}{ Chemical composition (wt\%) } \\
\cline { 3 - 6 } & & $\mathrm{MgO}$ & $\mathrm{Al}_{2} \mathrm{O}_{3}$ & $\mathrm{SiO}_{2}$ & $\mathrm{Fe}_{3} \mathrm{O}_{4}$ \\
\hline nV & 92.6 & 24.2 & 11.9 & 53.0 & 10.8 \\
$\mathrm{AVg}$ & 110.4 & 24.8 & 12.8 & 52.4 & 10.0 \\
$\mathrm{AV} \mathrm{N0.5}$ & 89 & 24.7 & 12.9 & 52.1 & 10.3 \\
$\mathrm{AVg} \mathrm{N0.5}$ & 84.1 & 19.4 & 11.3 & 57.7 & 11.6 \\
$\mathrm{AV} \mathrm{N1.0}$ & 65.5 & 17.3 & 9.3 & 60.0 & 13.3 \\
AVg N1.0 & 74.1 & 15.3 & 7.8 & 64.8 & 12.1 \\
AV N2.0 & 28.5 & 5.8 & 1.9 & 85.4 & 6.9 \\
AVg N2.0 & 56.3 & 4.0 & 1.9 & 87.9 & 6.2 \\
\hline
\end{tabular}

ground counterpart showed decreased amount of $\mathrm{Mg}$ and $\mathrm{Al}$ and slightly increased percentage of $\mathrm{Fe}$, that was leached only with higher acid concentrations. The changes suggest increased susceptibility of the fine ground vermiculite to acid attack. Si is located in the tetrahedral sheets that are more resistant to acid attack (Steudel et al., 2009; Pentrák et al., 2012), thus it was retained in the materials, although in the form of amorphous silica in the case where more concentrated acids were used for the activation (Table 1).

\subsubsection{Particle size distribution}

Fine grinding of the raw material ( $\mathrm{AVg}$ ) caused an increase in the percentage of the fraction between 65 and $45 \mu \mathrm{m}$, while decreasing the percentage of the fraction between 180 and $125 \mu \mathrm{m}$. The smallest fraction of the rough ground material (AV) was more susceptible to acid attack and it dissolved with increasing acid concentration. This fraction could be the product of natural weathering of vermiculite obtained after its exposition to the atmospheric conditions. It may rather consist of fragmented delaminated clay mineral, than of a material characterized by unaltered layered structure. Furthermore, as a result of leaching and fragmentation of the mineral, the percentage of the fraction between 125 and $65 \mu \mathrm{m}$ increased while the fraction between 180 and $125 \mu \mathrm{m}$ diminished. Similar behavior was observed for activation in $1.0 \mathrm{~mol} \mathrm{~L}^{-1} \mathrm{HNO}_{3}$. Significant decrease in the percentage of the fractions between 355 and $125 \mu \mathrm{m}$ and an increase in the percentage of the fractions below $65 \mu \mathrm{m}$ was observed after application of $2.0 \mathrm{~mol} \mathrm{~L}^{-1}$ acid. For the fine ground material, the activation even in low concentrations, caused a decrease in the percentage of the bigger fractions and an increase in the percentage of the fraction below $45 \mu \mathrm{m}$. With increasing concentration the percentage of the fraction between 125 and $65 \mu \mathrm{m}$ increased and the percentage of the fraction between 65 and $45 \mu \mathrm{m}$ decreased (Fig. 2).

\subsection{4. $X R D$}

The materials, $\mathrm{AV}$ and $\mathrm{AVg}$, showed typical reflections of vermiculite at $6.2^{\circ}(\mathrm{d}=14.2 \AA \mathrm{A}, 002), 12.3^{\circ}(\mathrm{d}=7.2 \AA, 004), 18.5^{\circ}(\mathrm{d}=4.8 \AA$, $006), 24.8^{\circ}(\mathrm{d}=3.6 \AA, 008), 31.2^{\circ}(\mathrm{d}=2.9 \AA, 0010), 37.5^{\circ}(\mathrm{d}=2.4 \AA$, $0012), 44.1^{\circ}(\mathrm{d}=2.05 \AA$, 0014) what is in agreement with JCPDS card nos. 01-076-0847 and 00-016-0613 (Santos et al., 2015) (Fig. 3A and B). Contrarily to the results obtained by Maqueda et al. (2007), upon wet milling no loss of periodicity perpendicular to the layer plane and a decrease in the dimension of the crystallites along the $00 l$ direction was observed by X-ray diffraction measurements. Such difference could be ascribed to the presence of water during the proposed wet milling procedure. This could have protected the material from excessive heat released during the milling process conducted typically in dry conditions, thus the structure was kept. The chemical treatment caused broadening and a decrease in the intensity of the vermiculite reflections (Fig. 3A, B, E and F) proportional to the concentration of acid solution used. Fragmentation of the materials was reflected by smaller crystallite size in the samples after acid activation (Fig. 4D). The reflection at $6.2^{\circ}$, consistent with a vermiculite phase with two, partly incomplete, water bilayers (Muiambo et al., 2010), shifted slightly towards lower angles

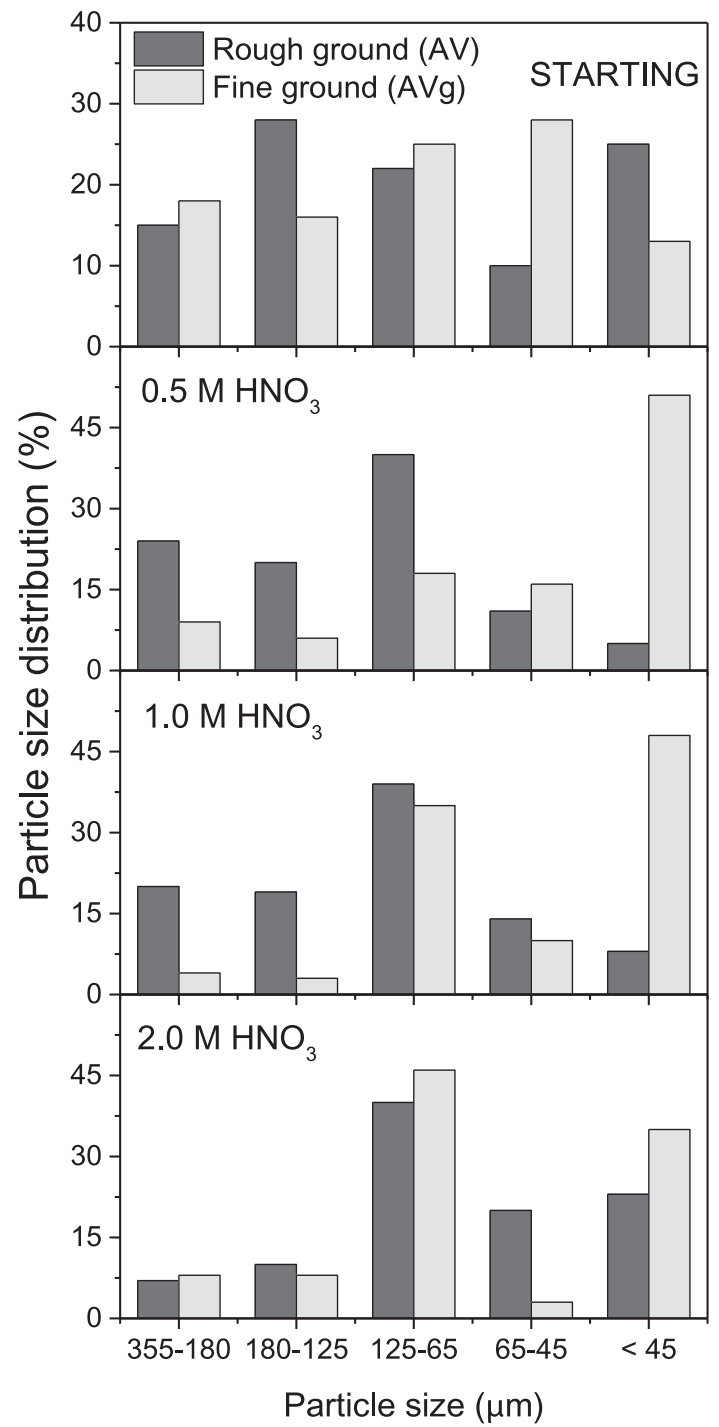

Fig. 2. Particle size distribution of mechanically and chemically modified vermiculite.

after the treatment reducing the intensity of the basal reflection (Fig. 4C), what may be attributed to different hydration states depending on the number of interlayer water molecules (Ferrage et al., 2005).

Acid treatment causes leaching of $\mathrm{Al}^{3+}, \mathrm{Mg}^{2+}$ and $\mathrm{Fe}^{3+}$ ions from the octahedral sheets (Table 1). This resulted in dissolution of the sheets and redeposition of a part of the leached components outside the layers, and formation of amorphous silica (broad reflection at around $26^{\circ}$ (Maqueda et al., 2007)). Consequently, the ordered, crystalline structure of the clay mineral was gradually transformed into a so called "house of cards" delaminated structure (Komadel and Madejova, 2006; Steudel et al., 2009; Chmielarz et al., 2012; Pentrák et al., 2012; Stawiński et al., 2016). Although all materials were affected by the acid, the effect was more intense in the fine ground samples (e.g., $0.5 \mathrm{~mol} \mathrm{~L}^{-1}$ acid applied to AVg changed the material's structure in a similar way as $1.0 \mathrm{~mol} \mathrm{~L}^{-1}$ acid applied to AV) (Fig. 3A sample AV N1.0 and Fig. 3B sample AV g N0.5)) due the defects in the mineral structure formed during acid activation (Pérez-Maqueda et al., 2004) that may render the clay mineral more prone to acid attack (Komadel and Madejova, 2006).

\subsubsection{Specific surface area}

The isotherms measured for the starting materials (AV and AVg) belong to the type II, which is characteristic for nonporous or 


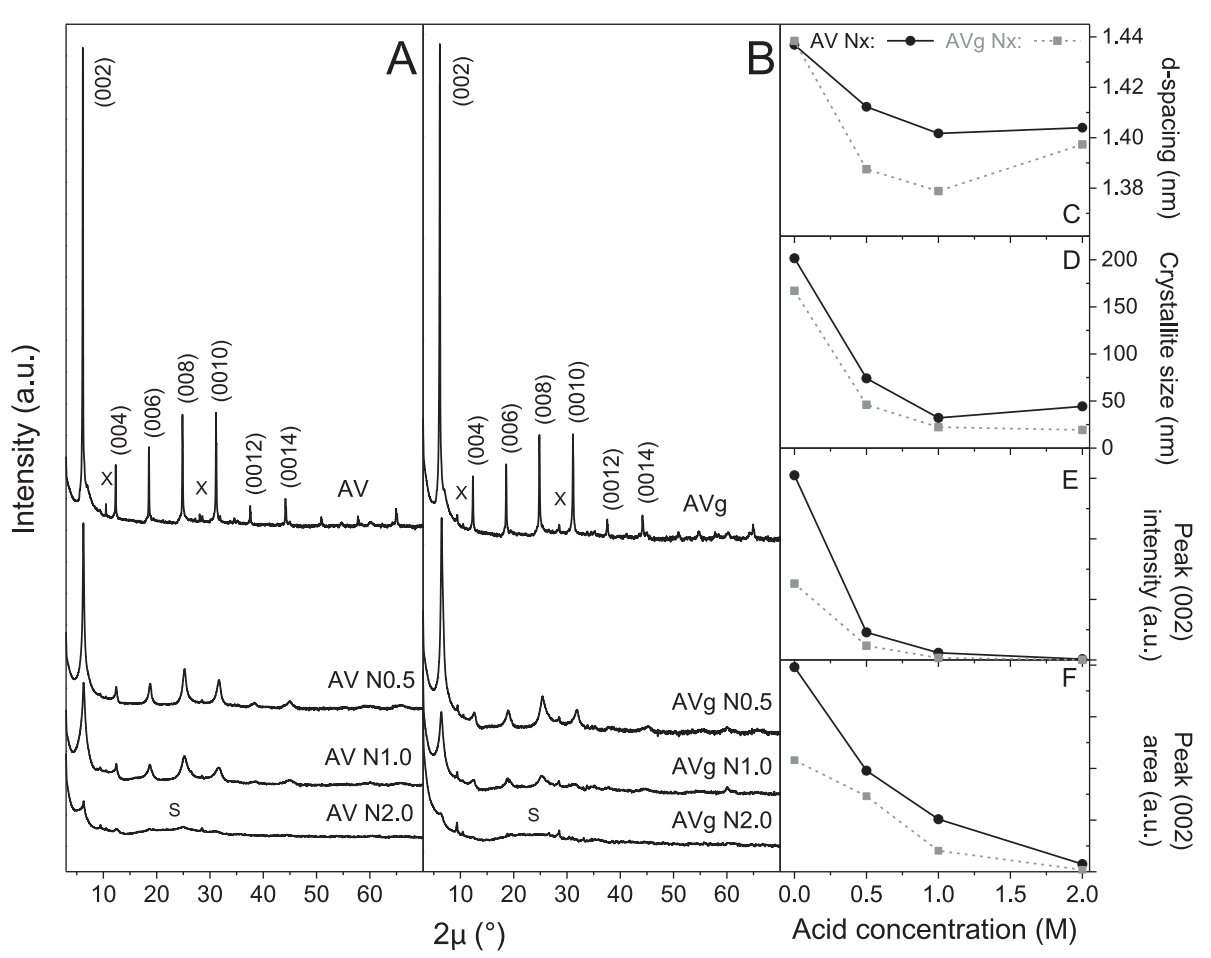

Fig. 3. XRD patterns of starting (A - rough ground, B - fine ground) and modified vermiculites ( $\mathrm{X}$ - mineral impurities, $\mathrm{S}$ - amorphous silica); and basal spacings and crystallinity indicators calculated for starting and modified vermiculites (C-F).

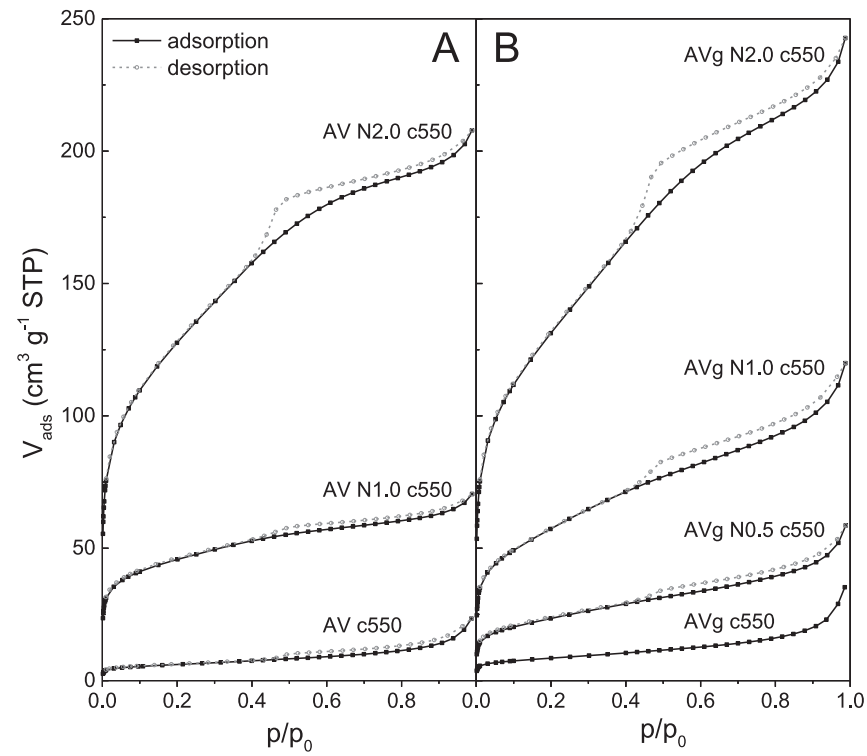

Fig. 4. $\mathrm{N}_{2}$ adsorption isotherms for starting and modified vermiculites.

macroporous materials (Thommes et al., 2015) (Fig. 4). Only very small increase in nitrogen adsorbed volume occurred in the range of partial pressure from 0.1 to 0.8 . A sharp increase in adsorbed volume, observed at $\mathrm{p} / \mathrm{p}_{0}$ above 0.8 , is caused by condensation of nitrogen in the intergrain spaces. The acid activation process resulted in increased volume of adsorbed nitrogen within this pressure range. This effect could be related to the presence of large non-uniform pores and the type of isotherm could be classified as IVa characteristic for mesoporous materials. A very sharp increase of nitrogen adsorption at low partial pressure together with increasing acid concentration was noticed which suggests formation of micropores. In the starting materials the hysteresis loop is narrow and broadens after acid leaching. The recorded hysteresis loops of all the samples except these treated in $2.0 \mathrm{~mol} \mathrm{~L}^{-1}$ acid and fine ground AVg N1.0 c550, were of H4 type. In the case where higher acid concentrations and mechanical activation were applied, the hysteresis is a combination of $\mathrm{H} 2 \mathrm{~b}$ and $\mathrm{H} 3$ type which corresponded to pore network with narrow and wide sections and possible interconnecting channels and slit-like pores, respectively (Gregg and Sing, 1991; Thommes et al., 2015). The pores size distribution is presented in Fig. 5.

The specific surface area $\left(\mathrm{S}_{\mathrm{BET}}\right)$ and external surface area $\left(\mathrm{S}_{\mathrm{EXT}}\right)$ of $\mathrm{AV}$ were slightly increased from 21 to $30 \mathrm{~m}^{2} \mathrm{~g}^{-1}$, and from 12 to $18 \mathrm{~m}^{2} \mathrm{~g}^{-1}$ upon fine grinding, respectively (Fig. 5C and D). Fine grinding did not affect the mesopores and their surface $\left(\mathrm{S}_{\mathrm{MESO}}\right)$ remained on the level of $4 \mathrm{~m}^{2} \mathrm{~g}^{-1}$, however the surface of the micropores ( $\mathrm{S}_{\text {MICRO }}$ ) increased from 5 to $7 \mathrm{~m}^{2} \mathrm{~g}^{-1}$ as well as the total pores volume ( $\mathrm{V}_{\text {TOTAL }}$ ) that changed from $0.016 \mathrm{~cm}^{3} \mathrm{~g}^{-1}$ to $0.055 \mathrm{~cm}^{3} \mathrm{~g}^{-1}$ (Fig. $5 \mathrm{E}, \mathrm{F}$ and G). Acid activation caused an increase in all of these parameters. The evolution of $S_{\mathrm{EXT}}$ was greatly influenced by the mechanical pretreatment. Although it increased upon acid activation for both materials, the increase was higher for the fine ground vermiculite and it reached approximately two fold higher value in compared to the rough ground mineral (i.e., 26 and $46 \mathrm{~m}^{2} \mathrm{~g}^{-1}$ for the rough and fine ground after treatment in $2.0 \mathrm{~mol} \mathrm{~L}^{-1}$ acid). Furthermore, $\mathrm{S}_{\mathrm{BET}}$ and $\mathrm{S}_{\mathrm{MESO}}$ reached comparable values after the treatment in $2.0 \mathrm{~mol} \mathrm{~L}^{-1}$ acid regardless the fine grinding (i.e., 458 and $475 \mathrm{~m}^{2} \mathrm{~g}^{-1}$, and 367 and $373 \mathrm{~m}^{2} \mathrm{~g}^{-1}$, respectively for the rough and fine ground material), the $\mathrm{V}_{\text {TOTAL }}$ increased to 0.321 and $0.375 \mathrm{~cm}^{3} \mathrm{~g}^{-1}$ respectively. Application of high acid concentration resulted in a decrease in the variation between the parameters of the fine and rough ground materials, however there was a discrepancy in the range of mild treatment conditions. The fine ground material treated with $1.0 \mathrm{~mol} \mathrm{~L}^{-1}$ acid had higher $\mathrm{S}_{\mathrm{BET}}$ and $\mathrm{S}_{\mathrm{MESO}}$, compared to its rough ground counterpart. On the other hand, the latter material treated in the same conditions developed microporosity faster than the fine ground sample. The rough ground material still had a significant percentage of bigger particles, thus as the crystal 


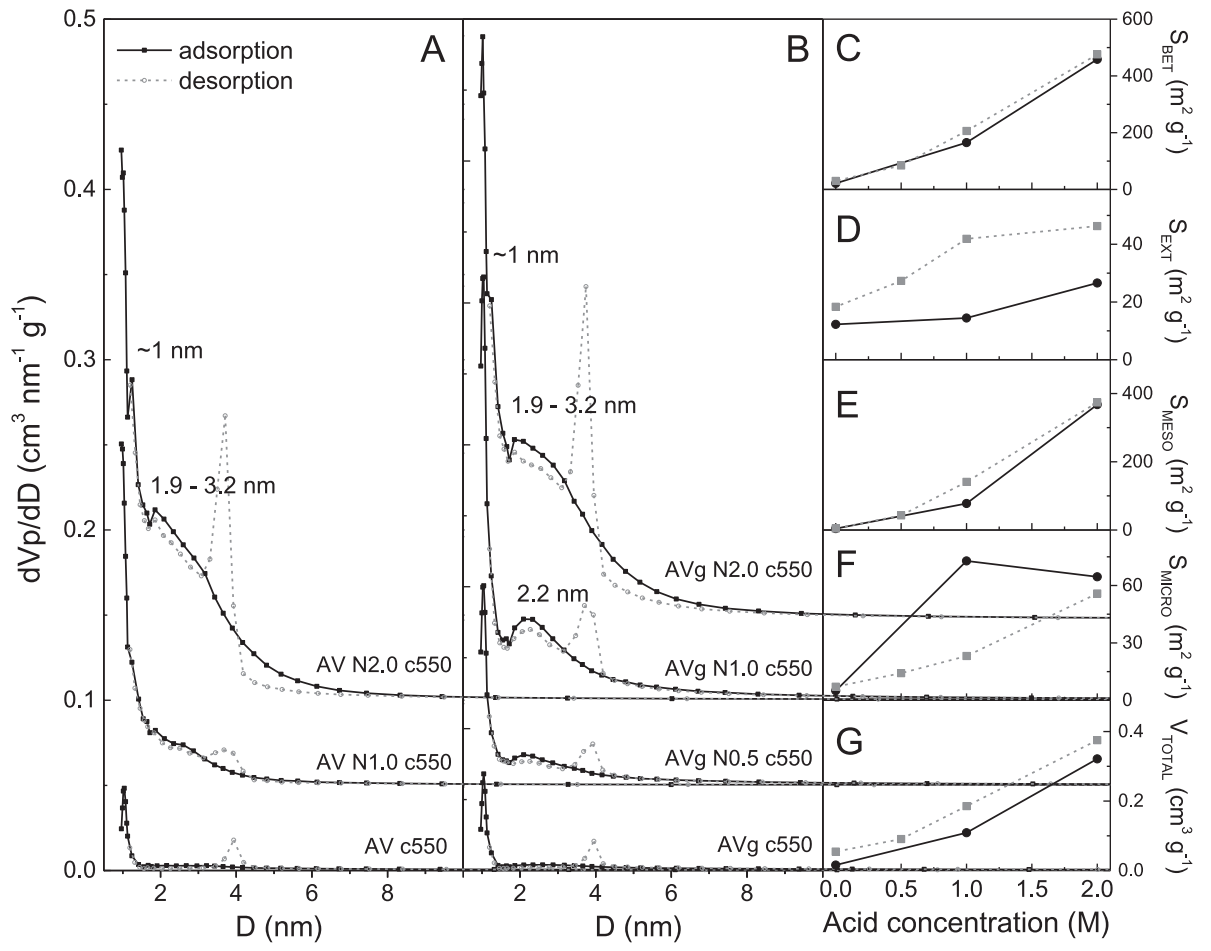

Fig. 5. Pore size distribution of starting and modified vermiculites (A - rough ground, B - fine ground), and textural parameters calculated for starting and modified vermiculites: C - BET specific surface area, D - external surface area, E and F - surface of meso- and micropores, respectively, $\mathrm{G}$ - total volume of pores.

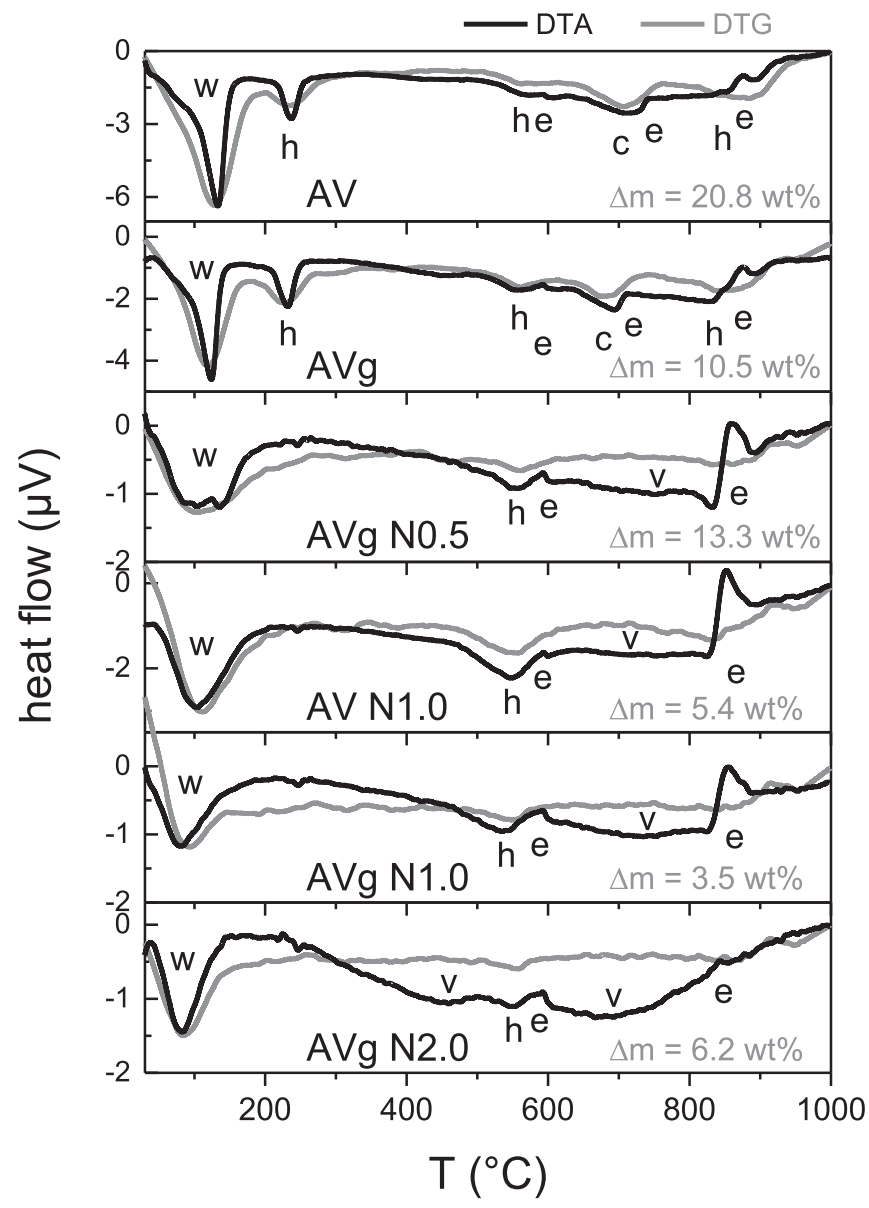

Fig. 6. Thermal analysis results of vermiculite-derived adsorbents; $w$ - release of interlayer water, $\mathrm{h}$ - dehydroxylation, $\mathrm{c}$ - decomposition of carbonates, $\mathrm{v}-$ sintering of amorphous silica, e - expanding of vermiculite, recrystallization. particles were leached, some microporosity was formed as a result of selective removal of the layer components. In the case of the fine ground sample (AVg N1.0 c550), where the fine fraction prevailed, the material was rather fragmented into small pieces upon acid attack, than cracks and cleavages on the surface on the layers formed, giving raise to microporosity, thus the $\mathrm{S}_{\text {MESO }}$ was higher and $\mathrm{S}_{\text {MICRO }}$ did not increase. Moreover, since the particles were finer, the $\mathrm{S}_{\mathrm{EXT}}$, which is the surface outside the pores, must be grater. This, together with the increased $\mathrm{V}_{\text {TOTAL }}$ originating in augmented mesoporosity, translated into higher $\mathrm{S}_{\mathrm{BET}}$.

\subsection{6. $D T A / D T G$}

The first observed phenomenon in the temperature ranges up to $200{ }^{\circ} \mathrm{C}$ could be associated with the loss of physically adsorbed water (Fig. 6). Dehydration started from desorption of the water adsorbed on the surface, then interlayer water molecules and water molecules bound to the interlayer cations (Földvári, 2011). The latter process was not observed in the acid activated samples as their interlayer species are mostly removed (Chmielarz et al., 2010). The removal of the moisture proceeded at lower temperatures in the case of the acid activated materials due to their increased specific surface area (Fig. 5C) lowered layer charge and consecutive decreased attraction forces between the layers (Schoonheydt and Johnston, 2006). For both starting materials, the peaks were well defined, but upon acid treatment the curve became broad and diffuses in nature what was related to changes in the kinetics of the decomposition process. The low temperature loop was highly dependent on relative humidity, moisture content and type of interlayer cation (Richards and Rowland, 1952). The endothermic loop occurring at mid-temperatures range was associated with major loss of hydroxyls form the octahedral layer (Richards and Rowland, 1952). Dehydroxylation of amorphous silica in the samples containing acid treated vermiculite (e.g. AVg N2.0) occurred at around $500{ }^{\circ} \mathrm{C}$ (Zhuravlev, 2000; Rives, 2006). Dehydroxylation was followed by an endothermicexothermic peak system at about $800-900{ }^{\circ} \mathrm{C}$ where the structure was destructed and the exothermic peak corresponds to the crystallization of enstatite (Földvári, 2011) or mullite (El Mouzdahir et al., 2009; 


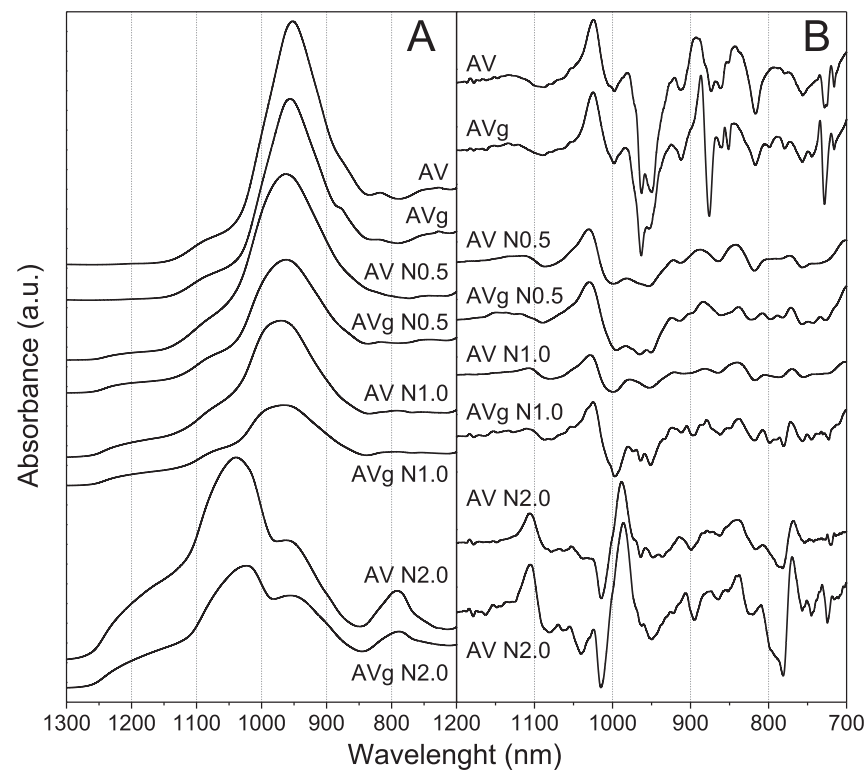

Fig. 7. ATR-FTIR spectra (A) and their 2nd derivative (B) of the mechanically and chemically modified vermiculites.

Smykatz-Kloss, 2012). It cannot be also excluded that the peaks at this temperature may also correspond to expanding which was additionally enhanced, in diluted acid concentrations $\left(0.5,1.0 \mathrm{~mol} \mathrm{~L}^{-1}\right)$, by removal of impurities blocking the structure of the starting materials.

\subsubsection{ATR-FTIR}

The ATR-FTIR spectra for the starting materials (AV, AVg) do not significantly differ, neither any significant changes were recorded between counterpart samples upon acid activation Fig. 7. The bands in the range between 1000 and $950 \mathrm{~cm}^{-1}$ are associated with vibrations of the $\mathrm{Si}-\mathrm{O}$ bond in the clay mineral layers (Stubičan and Roy, 1961; Madejova, 2003; Ritz et al., 2014). Bands with lower intensity resulted from bending and deformation vibrations in the octahedral sheet (e.g. $\mathrm{Al}-\mathrm{OH}, \mathrm{Al}-\mathrm{Mg}-\mathrm{OH}$ ) (Liu et al., 2011). The band at $870 \mathrm{~cm}^{-1}$ assigned

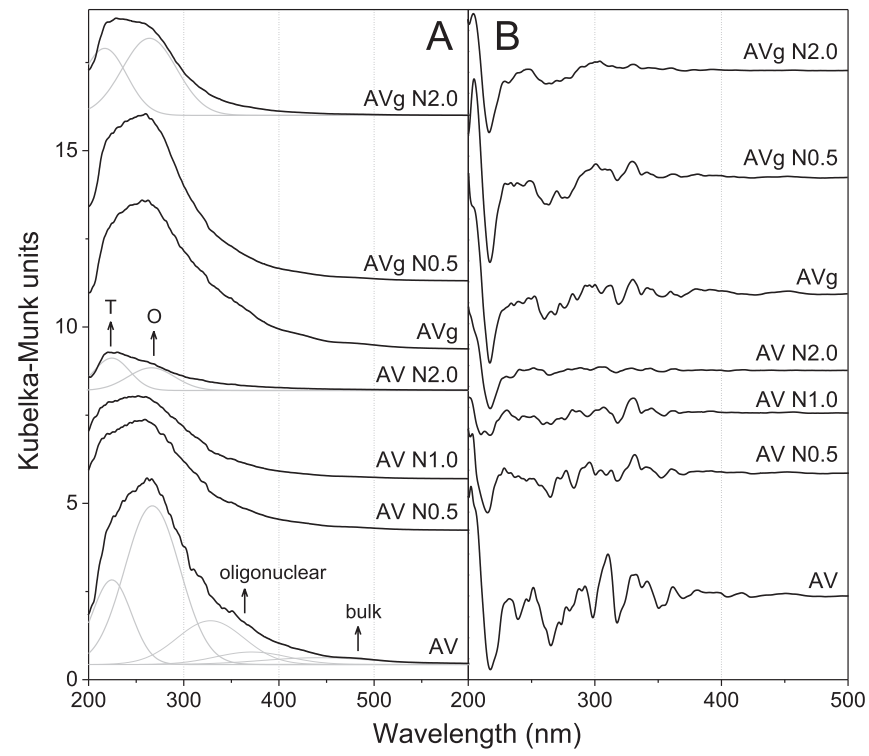

Fig. 8. UV-Vis-DRS spectra (A) and their 2nd derivative (B) of the mechanically and chemically modified vermiculites. to AlFeOH (Madejová and Komadel, 2001) and the bands at $815 \mathrm{~cm}^{-1}$ and $765 \mathrm{~cm}^{-1}$ correspond to tetrahedral $\mathrm{Al}-\mathrm{O}$ out-of-plane and $\mathrm{Al}-\mathrm{O}-\mathrm{Si}$ in-plane vibrations (Madejová and Komadel, 2001), respectively. The band at $795 \mathrm{~cm}^{-1}$ in the acid treated material can be attributed to free silica (Belver et al., 2002). The spectra of the acid activated materials were typical for vermiculites that underwent acid leaching (Stawiński et al., 2017b). The bands exhibited decreased intensity and a series of new bands associated with amorphous silica were present at 1200,1180,1045, 1020, 800 and $780 \mathrm{~cm}^{-1}$ (Madejová et al., 1998; Komadel and Madejova, 2006; Chmielarz et al., 2012; Barabaszová and Valášková, 2013; Ritz et al., 2014).

\subsubsection{UV-Vis-DRS}

The bands below $250 \mathrm{~nm}$ (around $215 \mathrm{~nm}$ ) are characteristic for the $\mathrm{O} \rightarrow \mathrm{Fe}^{3+}$ charge transfer in iron in tetrahedral (T) coordination. The range between 250 and $300 \mathrm{~nm}$ corresponds to such charge transfer in octahedral (O) coordination $\left(\mathrm{Fe}^{3+}\right.$ substituting for magnesium show a band in the range $245-250 \mathrm{~nm}$ ). The region between $300 \mathrm{~nm}$ and $400 \mathrm{~nm}$ is attributed to oligonuclear $\mathrm{Fe}_{\mathrm{x}} \mathrm{O}_{\mathrm{y}}$ clusters and bands above $400 \mathrm{~nm}$ originate in particles of $\mathrm{Fe}_{2} \mathrm{O}_{3}$ (Karickhoff and Bailey, 1973; Kumar et al., 2004; Pérez-Ramírez et al., 2004).

In both starting materials the iron was mostly located in the octahedral position. Upon acid activation the peak at around $260 \mathrm{~nm}$ lost intensity as the octahedral sheets were leached. After activation in $2.0 \mathrm{M}$ acid the reflection at around $220 \mathrm{~nm}$ became stronger that the one at $260 \mathrm{~nm}$. Moreover, the peaks' intensities were diminished due to removal of iron from the materials' structure (Fig. 8). This phenomenon was observed in all spectra regardless grinding. The peaks of the rough ground materials were also broader compared to their fine ground counterparts, suggesting higher degree on randomness in the relative orientation of the microcrystalline material. Such structure increases the light scattering that tends to increase the absorbance. Also when there is a charge transfer from octahedral iron (III) to oxo- ligands it may result in an intense background in the lower energy region (Karickhoff and Bailey, 1973). However, in the samples not subjected to fine grinding, the peaks at higher wavelengths range, (i.e., 300, 320, 350 and $370 \mathrm{~nm}$ ) had stronger intensity. The oligonuclear and bulk $\mathrm{Fe}_{\mathrm{x}} \mathrm{O}_{\mathrm{y}}$ clusters, possibly located outside the layers (Chmielarz et al., 2010,2012 ) were removed more efficiently when the samples were subjected to fine grinding before activation.

\subsubsection{Mössbauer spectroscopy}

The spectra (Fig. 9) exhibited strong asymmetry in the adsorption areas and could be interpreted as superposition of four quadruple doublets and one sextet. Two ferric doublets may be assigned to $\mathrm{Fe}^{3+}$, and two ferrous doublets of $\mathrm{Fe}^{2+}$. The presence of two doublets for each iron form may be attributed to the Fe-for-Al substitution on trans (M1) and cis (M2) sites in the octahedral layer (Vandenberghe and Grave, 2006). Alternatively Taylor and Routsala (1968) ascribed the iron with IS $=\sim 0.5 \mathrm{~mm} \mathrm{~s}^{-1}$ and $\mathrm{QS}=\sim 1 \mathrm{~mm} \mathrm{~s}^{-1}$ to $\mathrm{Fe}^{3+}$ in the tetrahedral position. The second interpretation seems more plausible as it is in accordance with the UV-Vis-DRS analysis of the materials that indicated the presence of the tetrahedral iron (Fig. 10). Vermiculite has high amount of iron (Table 1) and it is generally accepted that the more iron-rich the layer, the more vacant the M1 sites (Stucki, 2006) thus, no peak from octahedral iron in M1 position was identified, consequently the iron with $\mathrm{IS}=0.36 \mathrm{~mm} \mathrm{~s}^{-1}$ and $\mathrm{QS}=0.53 \mathrm{~mm} \mathrm{~s}^{-1}$ should be ascribed to M2 position in the octahedral sheet. The sextet present in the spectra could be attributed to iron oxide (i.e. $\alpha-\mathrm{Fe}_{2} \mathrm{O}_{3}$ ) (Tuček et al., 2013).

The material after fine grinding had similar iron distribution, the small changes may be attributed to air-oxidation of $\mathrm{Fe}^{2+}$ in the material upon fragmentation of the particles. Acid activation causes 
Fig. 9. The $295 \mathrm{~K}$ Mössbauer spectra of selected materials.
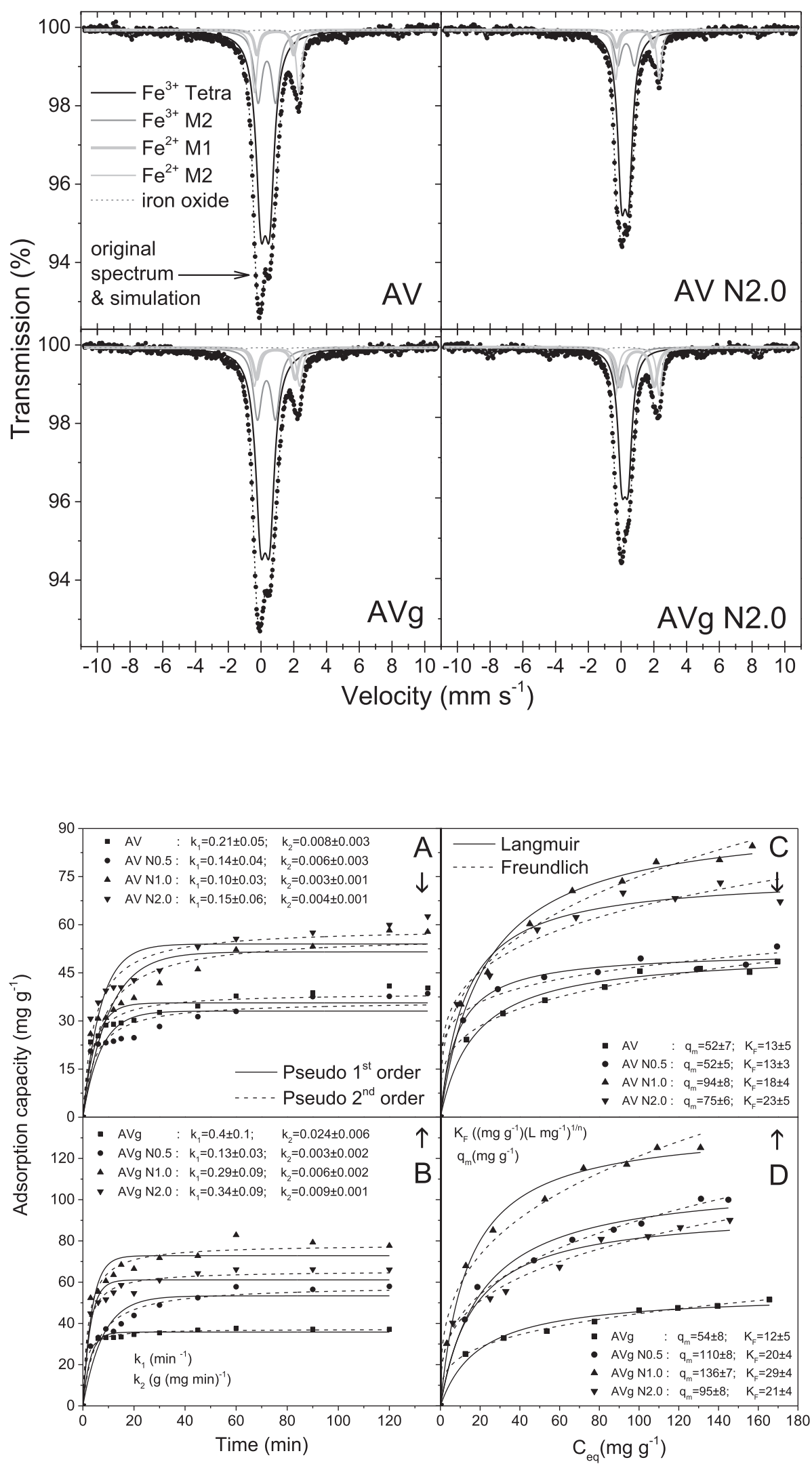

Fig. 10. Kinetic experimental data with fitted models and the kinetic parameters for rough ground (A) and fine ground (B) vermiculite treated with nitric acid of different concentrations and equilibrium experimental data with fitted models for rough ground (C) and fine ground (D) vermiculites. 
Appendix A. Appendix

Table A.1

Mössbauer spectral parameters for chemically and mechanically modified vermiculite.

\begin{tabular}{|c|c|c|c|c|c|c|}
\hline Sample & Iron valence & At. $(\%)$ & Isomer shift $\left(\mathrm{mm} \mathrm{s}^{-1}\right)$ & Quadrupole splitting $\left(\mathrm{mm} \mathrm{s}^{-1}\right)$ & Hyperfine magnetic field $(\mathrm{T})$ & Absorber line-width $\left(\mathrm{mm} \mathrm{s}^{-1}\right)$ \\
\hline \multirow[t]{5}{*}{$\mathrm{AV}$} & $\mathrm{Fe}^{3+}$ tetra & 21 & 0.47 & 1.07 & - & 0.47 \\
\hline & $\mathrm{Fe}^{3+} \mathrm{M} 2$ & 60 & 0.36 & 0.53 & - & 0.60 \\
\hline & $\mathrm{Fe}^{2+} \mathrm{M} 1$ & 12 & 1.07 & 2.71 & - & 0.27 \\
\hline & $\mathrm{Fe}^{2+} \mathrm{M} 2$ & 5 & 0.98 & 2.24 & - & 0.27 \\
\hline & Iron oxide & 2 & 0.40 & -0.14 & 50.8 & 0.34 \\
\hline \multirow[t]{5}{*}{$\mathrm{AVg}$} & $\mathrm{Fe}^{3+}$ tetra & 22 & 0.44 & 1.10 & - & 0.52 \\
\hline & $\mathrm{Fe}^{3+} \mathrm{M} 2$ & 61 & 0.36 & 0.54 & - & 0.63 \\
\hline & $\mathrm{Fe}^{2+} \mathrm{M} 1$ & 8 & 1.08 & 2.76 & - & 0.32 \\
\hline & $\mathrm{Fe}^{2+} \mathrm{M} 2$ & 8 & 1.03 & 2.35 & - & 0.37 \\
\hline & Iron oxide & 1 & 0.41 & -0.13 & 50.8 & 0.22 \\
\hline \multirow[t]{5}{*}{ AV N2.0 } & $\mathrm{Fe}^{3+}$ tetra & 15 & 0.38 & 0.94 & - & 0.40 \\
\hline & $\mathrm{Fe}^{3+} \mathrm{M} 2$ & 48 & 0.34 & 0.39 & - & 0.46 \\
\hline & $\mathrm{Fe}^{2+} \mathrm{M} 1$ & 13 & 1.11 & 2.66 & - & 0.26 \\
\hline & $\mathrm{Fe}^{2+} \mathrm{M} 2$ & 16 & 1.10 & 2.06 & - & 0.42 \\
\hline & Iron oxide & 8 & 0.31 & -0.06 & 50.6 & 0.57 \\
\hline \multirow[t]{5}{*}{ AVg N2.0 } & $\mathrm{Fe}^{3+}$ tetra & 14 & 0.42 & 1.01 & - & 0.40 \\
\hline & $\mathrm{Fe}^{3+} \mathrm{M} 2$ & 66 & 0.35 & 0.43 & - & 0.47 \\
\hline & $\mathrm{Fe}^{2+} \mathrm{M} 1$ & 13 & 1.11 & 2.65 & - & 0.24 \\
\hline & $\mathrm{Fe}^{2+} \mathrm{M} 2$ & 5 & 0.96 & 2.24 & - & 0.26 \\
\hline & Iron oxide & 2 & 0.32 & -0.23 & 51.4 & 0.11 \\
\hline
\end{tabular}


Table A.2

Results of Astrazon Red adsorption - kinetic and isotherm models' parameters.

\begin{tabular}{|c|c|c|c|c|c|c|c|c|c|c|}
\hline \multirow[t]{2}{*}{ Model } & & \multirow[t]{2}{*}{ Parameter } & \multicolumn{8}{|l|}{ SAMPLE } \\
\hline & & & AV & AV N0.5 & AV N1.0 & AV N2.0 & $\mathrm{AVg}$ & AVg N0.5 & AVg N1.0 & AVg N2.0 \\
\hline \multirow[t]{11}{*}{ Kinetics } & pseudo-1st & $\mathrm{q}_{\mathrm{e}}\left(\mathrm{mg} \mathrm{g}^{-1}\right)$ & $36 \pm 3$ & $33 \pm 4$ & $52 \pm 6$ & $54 \pm 6$ & $36 \pm 1$ & $53 \pm 6$ & $73 \pm 6$ & $61 \pm 4$ \\
\hline & order & $\mathrm{k}_{1}\left(\min ^{-1}\right)$ & $0.21 \pm 0.05$ & $0.14 \pm 0.04$ & $0.10 \pm 0.03$ & $0.15 \pm 0.06$ & $0.4 \pm 0.1$ & $0.13 \pm 0.03$ & $0.29 \pm 0.09$ & $0.34 \pm 0.09$ \\
\hline & & $s^{2}$ & 16.55 & 24.14 & 41.79 & 43.46 & 13.84 & 32.122 & 43.63 & 24.4 \\
\hline & & $\mathrm{R}_{\text {adj }}^{2}$ & 0.853 & 0.766 & 0.834 & 0.838 & 0.883 & 0.879 & 0.908 & 0.926 \\
\hline & pseudo- 2nd & $\mathrm{q}_{\mathrm{e}}\left(\mathrm{mg} \mathrm{g}^{-1}\right)$ & $38 \pm 3$ & $36 \pm 4$ & $56 \pm 6$ & $59 \pm 5$ & $37 \pm 1$ & $58 \pm 5$ & $78 \pm 4$ & $65 \pm 3$ \\
\hline & order & $\mathrm{k}_{2}\left(\mathrm{~g}(\mathrm{mg} \min )^{-1}\right)$ & $0.008 \pm 0.003$ & $0.006 \pm 0.001$ & $0.003 \pm 0.001$ & $0.004 \pm 0.001$ & $0.024 \pm 0.006$ & $0.003 \pm 0.001$ & $0.006 \pm 001$ & $0.009 \pm 0.001$ \\
\hline & & $s^{2}$ & 6.16 & 11.54 & 18.75 & 17.08 & 8.61 & 12.21 & 15.02 & 7.3 \\
\hline & & $\mathrm{R}_{\mathrm{adj}}^{2}$ & 0.946 & 0.888 & 0.925 & 0.936 & 0.927 & 0.954 & 0.968 & 0.978 \\
\hline & best fit & F-test & no difference & no difference & no difference & no difference & no difference & $\begin{array}{l}\text { no } \\
\text { difference }\end{array}$ & $\begin{array}{l}\text { no } \\
\text { difference }\end{array}$ & Pseudo 2nd \\
\hline & & AIC & Pseudo 2nd & Pseudo 2nd & Pseudo 2nd & Pseudo 2nd & Pseudo 2nd & Pseudo 2nd & Pseudo 2nd & Pseudo 2nd \\
\hline & & BIC & Pseudo 2nd & Pseudo 2nd & Pseudo 2nd & Pseudo 2nd & Pseudo 2nd & Pseudo 2nd & Pseudo 2nd & Pseudo 2nd \\
\hline \multirow[t]{11}{*}{ Equilibrium } & Langmuir & $\mathrm{q}_{\mathrm{m}}\left(\mathrm{mg} \mathrm{g}^{-1}\right)$ & $51 \pm 7$ & $52 \pm 5$ & $94 \pm 8$ & $75 \pm 6$ & $55 \pm 8$ & $110 \pm 8$ & $136 \pm 7$ & $95 \pm 8$ \\
\hline & & $\mathrm{K}_{\mathrm{L}}\left(\mathrm{L} \mathrm{mg}^{-1}\right)$ & $0.06 \pm 0.04$ & $0.12 \pm 0.08$ & $0.04 \pm 0.02$ & $0.08 \pm 0.03$ & $0.05 \pm 0.03$ & $0.05 \pm 0.01$ & $0.07 \pm 0.02$ & $0.06 \pm 0.02$ \\
\hline & & $s^{2}$ & 3.11 & 4.28 & 8.46 & 14.39 & 6.48 & 19.98 & 18.29 & 53.6 \\
\hline & & $\mathrm{R}_{\mathrm{adj}}^{2}$ & 0.987 & 0.984 & 0.989 & 0.974 & 0.975 & 0.980 & 0.990 & 0.997 \\
\hline & Freundlich & $\begin{array}{l}\mathrm{K}_{\mathrm{F}}\left(\left(\mathrm{mg} \mathrm{g}^{-1}\right)\left(\mathrm{L} \mathrm{mg}^{-1}\right)\right. \\
1 / \mathrm{n})\end{array}$ & $13 \pm 5$ & $13 \pm 3$ & $18 \pm 4$ & $23 \pm 5$ & $12 \pm 5$ & $21 \pm 4$ & $29 \pm 4$ & $21 \pm 4$ \\
\hline & & $\mathrm{n}$ & $4 \pm 1$ & $6 \pm 2$ & $3.2 \pm 0.5$ & $4 \pm 1$ & $4 \pm 1$ & $3.2 \pm 0.4$ & $3.2 \pm 0.3$ & $3.4 \pm 0.5$ \\
\hline & & $s^{2}$ & 2.37 & 5.43 & 7.81 & 16.28 & 0.78 & 8.05 & 35.87 & 8.55 \\
\hline & & $\mathrm{R}_{\mathrm{adj}}^{2}$ & 0.990 & 0.979 & 0.989 & 0.970 & 0.997 & 0.992 & 0.981 & 0.990 \\
\hline & best fit & F-test & no difference & no difference & no difference & no difference & Freundlich & $\begin{array}{l}\text { no } \\
\text { difference }\end{array}$ & $\begin{array}{l}\text { no } \\
\text { difference }\end{array}$ & no difference \\
\hline & & AIC & Freundlich & Langmuir & Freundlich & Langmuir & Freundlich & Freundlich & Langmuir & Freundlich \\
\hline & & BIC & Freundlich & Langmuir & inconclusive & inconclusive & Freundlich & Freundlich & Langmuir & Freundlich \\
\hline
\end{tabular}


dissolution of the octa- and tetrahedral sheets simultaneously (Stucki, 2006) but for the rough ground acid treated material, the removal of iron from the octahedral sheets was somewhat faster compared to the removal from the tetrahedral sheet with relation to its fine ground counterpart. The latter material was more homogeneous, it had smaller particles additionally riddled with defects, that all may have contributed to more homogeneous dissolution of both sheets. Thus again proving increased susceptibility of fine ground vermiculite to acid attack. Moreover, fine grinding caused removal of iron oxides what is in accordance with the UV-Vis-DRS studies. Mössbauer spectral parameters for the chosen investigated materials are presented in Table A.1 in the Appendix.

\subsection{Adsorption experiments}

Fine grinding of the material shortened the time required to reach the equilibrium from approximately 60 to $30 \mathrm{~min}$ and increased the adsorption rates from $0.008 \pm 0.003$ to $0.024 \pm 0.006{\mathrm{~g}(\mathrm{mg} \mathrm{min})^{-1}}^{-1}$ for the rough ground $(\mathrm{AV})$ and fine ground $(\mathrm{AVg})$ materials, respectively (Fig. 10A and B). The rates generally decreased upon acid activation and were the lowest for the samples having the highest adsorption capacity (i.e. AV N1.0 and AVg N0.5). Adsorption of the dye followed pseudo 2 nd order model in all materials.

Fine grinding of the material, without applying acid treatment, did not affect the material's adsorption capacity, however the capacity changed when the clay mineral was subjected to acid. Whereas application of $0.5 \mathrm{~mol} \mathrm{~L}^{-1} \mathrm{HNO}_{3}$ to $\mathrm{AV}$ did not change its adsorption capacity, the same treatment of $\mathrm{AVg}$ caused an increase from $55 \pm 8$ to $110 \pm 8 \mathrm{mg} \mathrm{g}^{-1}$. The optimal treatment conditions for both samples were in $1.0 \mathrm{M} \mathrm{HNO}_{3}$ but the adsorption capacity for $\mathrm{AVg}$ increased more (i.e., from $55 \pm 8$ to $136 \pm 7 \mathrm{mg} \mathrm{g}^{-1}$ ) than for $\mathrm{AV}$ (i.e., $51 \pm 7$ to $94 \pm 8 \mathrm{mg} \mathrm{g}^{-1}$ ). Concentrations higher than $1.0 \mathrm{M}$ resulted in deterioration in the adsorption capacities in both cases (Fig. 10C and D).

Adsorption on the staring materials followed the Freundlich's model. When the rough ground sample was treated with $0.5 \mathrm{~mol} \mathrm{~L}^{-1}$ acid, the mechanism changed to the Langmuir's model, when it was treated in $1.0 \mathrm{~mol} \mathrm{~L}^{-1}$, the Freundlich's model was a better fit, and when it was treated with $2.0 \mathrm{~mol} \mathrm{~L}^{-1}$ acid the adsorption follow the Langmuir's model. Opposite situation was true for the materials subjected to fine grinding before the activation. In that case the best fits were Freundlich's, Langmuir's and Freundlich's models, respectively, for the vermiculite treated with $0.5,1.0$ and $2.0 \mathrm{~mol} \mathrm{~L}^{-1} \mathrm{HNO}_{3}$. Full list of models' parameters is shown in Table A.2 in the Appendix.

The reduction of the time necessary to reach the equilibrium, thus the higher adsorption rate, may be due to smaller particles of the material and its cracked surface facilitating migration of the adsorbate in between the layers as this may occur, not only at the edges of the particles, but also through these cracks. The effect of the layered structure and diffusion between the layers was not that significant in the acid activated materials where the structure was distorted, and the adsorption rate was similar (within the same order of magnitude). The maximum adsorption capacities were higher compared to the starting materials due to formation of new adsorption centra, increase in the specific surface area and reduction of the layer charge, what facilitated the migration of the dye molecules into the interlayer space.

The changes of behavior indicated by different models fitting better the experimental data, may be due various modifications that the surface of the material underwent in each treatment step. The surface became cracked and riddled with cleavages, the edges of the particles change from rounded to ragged, the material became less crystalline and amorphous silica phase was created, moreover the surface chemistry of the particles changed due to its dissolution and leaching of its components as specific surface area, external surface area and microporosity increased. All these changes, depending on their extent, may have rendered the surface more or less heterogeneous, thus the Langmuir's or Freundlich's model fitted the data better, respectively. Notwithstanding, it is interesting that, except for the starting materials, whenever fine grinding was applied the adsorbent's behavior changed. However, it should be remarked that adjusted $\mathrm{R}^{2}$ coefficients were very high and comparison of best fit has shown in several samples no preference towards one specific model. It cannot be excluded that both kinds of adsorption (homogeneous vs. heterogeneous, monolayer vs. multilayer) play role in observed process. Nonetheless, most of the time, adsorption is controlled by various factors, thus the adsorption isotherm equations, as well as rate laws should be rather considered as helpful means to compare given materials and to predict adsorption capacity to design adsorption units, than tools to unambiguously determine actual phenomena taking place (Hameed and El-Khaiary, 2008; Sposito, 2008).

\section{Conclusions}

Fine wet grinding of vermiculite resulted in fragmentation of the material's particles. The surface of the layers become cracked and riddled with cleavages, their edges changes from rounded to ragged. The grinding, however, did not significantly alter the crystallinity, chemical composition and specific surface area of the material due to presence of water protecting material against excessive temperature increase, but some species of hydroxides were removed and cation exchange capacity (CEC) increased in the process. The fine ground material was more susceptible to acid leaching that caused dissolution of the layers and removal of their components, leaving materials with significantly decreased crystallinity and comprised mainly of amorphous silica when higher concentrations were applied. This was followed by a decrease in the CEC, an increase in the specific surface and external surface areas, and the total volume of pores as a result of development of meso- and microporosity. Micropores were developed faster and in lower acid concentrations in the rough ground sample, while the external surface area and total pores volume increased faster in the fine ground samples.

The changes in the materials reflected in their adsorption capacities. By applying fine mechanical fragmentation it was possible to obtain materials with similar adsorption capacities using an acid solution much lower than the original concentration. Moreover, while keeping the original concentration and subjecting the material to fine grinding, the final product reached even higher adsorption capacities. Thus, the environmental impact of acid activation of vermiculite can be diminished by application of lower acid concentration while obtaining of an adsorbent with better performance.

\section{Acknowledgements}

This work, within the scope of the project of Labóratorio Associado para Química Verde - Technologia e Processos Limpos - UID/QUI/ 50006 , is financed by national founds of FCT/MEC and co-financed by Fundos FEDER (POCI-01-0145-FEDER-007265) within the scope of the partnership agreement PT2020. Part of the research was carried out with the equipment purchased thanks to the financial support of the European Regional Development Fund in the framework of the Polish Innovation Economy Operational Program (contract no. POIG.02.01.00-12-023/08). To all financing sources the authors are greatly indebted. 


\section{References}

Anastas, P.T., Warner, J.C., 1998. Green Chemistry: Theory and Practice. Oxford University Press.

Angın, D., Köse, T.E., Selengil, U., 2013. Production and characterization of activated carbon prepared from safflower seed cake biochar and its ability to absorb reactive dyestuff. Appl. Surf. Sci. 280, 705-710.

Barabaszová, K.Č., Valášková, M., 2013. Characterization of vermiculite particles after different milling techniques. Powder Technol. 239, 277-283.

Belver, C., Bañares Muñoz, M.A., Vicente, M.A., 2002. Chemical activation of a kaolinite under acid and alkaline conditions. Chem. Mater. 14, 2033-2043.

Bergaya, F., Lagaly, G., 2006. General introduction: clays, clay minerals, and clay science. In: Bergaya, F., Theng, B.K.G., Lagaly, G. (Eds.), Handbook of Clay Science. Elsevier Ltd..

Bhatnagar, A., Jain, A.K., 2005. A comparative adsorption study with different industrial wastes as adsorbents for the removal of cationic dyes from water. J. Colloid Interface Sci. 281, 49-55.

Chmielarz, L., Kowalczyk, A., Michalik, M., Dudek, B., Piwowarska, Z., Matusiewicz, A., 2010. Acid-activated vermiculites and phlogophites as catalysts for the DeNOx process. Appl. Clay Sci. 49, 156-162.

Chmielarz, L., Wojciechowska, M., Rutkowska, M., Adamski, A., Wegrzyn, A., Kowalczyk, A., Dudek, B., Boroń, P., Michalik, M., Matusiewicz, A., 2012. Acid-activated vermiculites as catalysts of the DeNOx process. Catal. Today 191, 25-31.

Duman, O., Tunç, S., 2008. Electrokinetic properties of vermiculite and expanded vermiculite: effects of $\mathrm{pH}$, clay concentration and mono- and multivalent electrolytes. Sep. Sci. Technol. 43, 3755-3776.

El Mouzdahir, Y., Elmchaouri, A., Mahboub, R., Gil, A., Korili, S.A., 2009. Synthesis of nano-layered vermiculite of low density by thermal treatment. Powder Technol. 189, 2-5.

Ferrage, E., Lanson, B., Malikova, N., Plançon, A., Sakharov, B.A., Drits, V.A., 2005. New insights on the distribution of interlayer water in bi-hydrated smectite from X-ray diffraction profile modeling of 001 reflections. Chem. Mater. 17, 3499-3512.

Földvári, M., 2011. Handbook of Thermogravimetric System of Minerals and Its Use in Geological Practice. Geological Institute of Hungary (= Magyar Állami Földtani Intézet).

Forgacs, E., Cserháti, T., Oros, G., 2004. Removal of synthetic dyes from wastewaters: a review. Environ. Int. 30, 953-971.

Freundlich, H.M.F., 1906. Über die adsorption in läsungen. Z. Phys. Chem. 57, 385-470. Gregg, S.J., Sing, K.S.W., 1991. Adsorption, Surface Area, and Porosity. Academic Press.

Gupta, V.K., Ali, I., 2012. Environmental Water: Advances in Treatment, Remediation and Recycling. Elsevier.

Hadi, P., Sharma, S.K., Gordon McKay, G., 2015. Removal of dyes from effluents using biowaste-derived adsorbents. In: Sharma, S.K. (Ed.), Green Chemistry for Dyes Removal from Waste Water: Research Trends and Applications. Wiley.

Hameed, B.H., El-Khaiary, M.I., 2008. Sorption kinetics and isotherm studies of a cationic dye using agricultural waste: broad bean peels. J. Hazard. Mater. 154, 639-648.

Ho, Y.S., McKay, G., 1999. Pseudo-second order model for sorption processes. Process Biochem. 34, 451-465.

Karickhoff, S.W., Bailey, G.W., 1973. Optical absorption spectra of clay minerals. Clay Clay Miner. 21, 59-70.

Komadel, P., Madejova, J., 2006. Acid activation of clay minerals. In: Bergaya, F., Theng, B.K.G., Lagaly, G. (Eds.), Handbook of Clay Science. Elsevier Ltd.

Kumar, M.S., Schwidder, M., Grünert, W., Brückner, A., 2004. On the nature of different iron sites and their catalytic role in Fe-ZSM-5 DeNOx catalysts: new insights by a combined EPR and UV/VIS spectroscopic approach. J. Catal. 227, 384-397.

Kuzmanovic, M., Banjac, Z., Ginebreda, A., Petrovic, M., Barcelo, D., 2013. Prioritization: selection of environmentally occurring pharmaceuticals to be monitored. In: Petrovic, M., Perez, S., Barcelo, D. (Eds.), Analysis, Removal, Effects and Risk of Pharmaceuticals in the Water Cycle, 2nd Edition. Elsevier.

Lagaly, G., Ogava, M., Dekany, I., 2006. Clay mineral organic interactions. In: Bergaya, F., Theng, B.K.G., Lagaly, G. (Eds.), Handbook of Clay Science. Elsevier Ltd..

Lagergren, S., 1898. About theory of so-called adsorption of soluble substances. Kongl. Vetenskaps Acad. Handlingar 24, 1-39.

Langmuir, I., 1918. The adsorption of gases on plane surfaces of glass, mica and platinum. J. Am. Chem. Soc. 40, 1361-1403.

Liu, D., Yuan, P., Liu, H., Cai, J., Qin, Z., Tan, D., Zhou, Q., He, H., Zhu, J., 2011. Influence of heating on the solid acidity of montmorillonite: a combined study by DRIFT and Hammett indicators. Appl. Clay Sci. 52, 358-363.

Madejova, J., 2003. FTIR techniques in clay mineral studies. Vib. Spectrosc. 31, 1-10.

Madejová, J., Komadel, P., 2001. Baseline studies of the clay minerals society source clays: infrared methods. Clay Clay Miner. 49, 410-432.

Madejová, J., Bujdák, J., Janek, M., Komadel, P., 1998. Comparative FT-IR study of structural modifications during acid treatment of dioctahedral smectites and hectorite. Spectrochim. Acta A Mol. Biomol. Spectrosc. 54, 1397-1406.

Maqueda, C., Romero, A.S., Morillo, E., Pérez-Rodríguez, J.L., 2007. Effect of grinding on the preparation of porous materials by acid-leached vermiculite. J. Phys. Chem. Solids 68, 1220-1224.

Maqueda, C., Perez-Rodriguez, J.L., Šubrt, J., Murafa, N., 2009. Study of ground and unground leached vermiculite. Appl. Clay Sci. 44, 178-184.

Muiambo, H.F., Focke, W.W., Atanasova, M., der Westhuizen, I., Tiedt, L.R., 2010. Thermal properties of sodium-exchanged palabora vermiculite. Appl. Clay Sci. 50, $51-57$.

Peake, B., Braund, R., Tong, A., Tremblay, L.A., 2016. The Life-Cycle of Pharmaceuticals in the Environment. Woodhead Publishing, Elsevier.

Pentrák, M., Czímerová, A., Madejová, J., Komadel, P., 2012. Changes in layer charge of clay minerals upon acid treatment as obtained from their interactions with methylene blue. Appl. Clay Sci. 55, 100-107.

Pereira, L., Alves, M., 2011. Dyes-environmental impact and remediation. In: Malik, A., Grohmann, E. (Eds.), Environmental Protection Strategies for Sustainable Development. Springer Science \& Business Media.

Pérez-Maqueda, L.A., de Haro, M.C.J., Poyato, J., Pérez-Rodríguez, J.L., 2004. Comparative study of ground and sonicated vermiculite. J. Mater. Sci. 39, 5347-5351.

Pérez-Ramírez, J., Santhosh Kumar, M., Brückner, A., 2004. Reduction of $\mathrm{N}_{2} \mathrm{O}$ with CO over FeMFI zeolites: influence of the preparation method on the iron species and catalytic behavior. J. Catal. 223, 13-27.

Perez-Rodriguez, J.L., Maqueda, C., Murafa, N., Šubrt, J., Balek, V., Pulišová, P., Lančok, A., 2011. Study of ground and unground leached vermiculite II. Thermal behaviour of ground acid-treated vermiculite. Appl. Clay Sci. 51, 274-282.

Raman, K.V., Mortland, M.M., 1966. External specific surface area of vermiculite. Am. Mineral. 51, 1787.

Richards, A., Rowland, A., 1952. Part III: methods of identifying clays and the interpretation of results differential thermal analysis of clays and carbonates. Clay Clay Miner. 1.

Ritz, M., Zdrálková, J., Valášková, M., 2014. Vibrational spectroscopy of acid treated vermiculites. Vib. Spectrosc. 70, 63-69.

Rives, V., 2006. Study of layered double hydroxides by thermal methods. In: Rives, V. (Ed.), Layered Double Hydroxides: Present and Future. Nova Science Publishers, Inc., New York.

Roy, A., Forano, C., Besse, J.P., 2006. Layered double hydroxides: synthesis and postsynthesis modification. In: Rives, V. (Ed.), Layered Double Hydroxides: Present and Future. Nova Science Publishers, Inc., New York.

Rozada, F., Calvo, L.F., García, A.I., Martín-Villacorta, J., Otero, M., 2003. Dye adsorption by sewage sludge-based activated carbons in batch and fixed-bed systems. Bioresour. Technol. 87, 221-230.

Santos, S.S.G., Silva, H.R.M., de Souza, A.G., Alves, A.P.M., da Silva Filho, E.C., Fonseca, M.G., 2015. Acid-leached mixed vermiculites obtained by treatment with nitric acid. Appl. Clay Sci. 104, 286-294.

Schoonheydt, R.A., Johnston, C.T., Theng, B.K.G., Lagal, G., 2006. Surface and interface chemistry of clay minerals. In: Bergaya, F. (Ed.), Handbook of Clay Science. Elsevier.

Sevekow, U., 2003. Health and safety aspects. In: Hunger, K. (Ed.), Industrial Dyes. Chemistry, Properties, Applications. Wiley-Vch, Weinheim.

Smykatz-Kloss, W., 2012. Differential Thermal Analysis: Application and Results in Mineralogy. Springer, Berlin Heidelberg.

Sposito, G., 2008. The Chemistry of Soils. Oxford University Press, New York.

Stawiński, W., Freitas, O., Chmielarz, L., Węgrzyn, A., Komędera, K., Błachowski, A., Figueiredo, S., 2016. The influence of acid treatments over vermiculite based material as adsorbent for cationic textile dyestuffs. Chemosphere 153, 115-129.

Stawiński, W., Węgrzyn, A., Dańko, T., Freitas, O., Figueiredo, S., Chmielarz, L., 2017a. Acid-base treated vermiculite as high performance adsorbent: insights into the mechanism of cationic dyes adsorption, regeneration, recyclability and stability studies. Chemosphere 173, 107-115.

Stawiński, W., Węgrzyn, A., Freitas, O., Chmielarz, L., Mordarski, G., Figueiredo, S., 2017b. Simultaneous removal of dyes and metal cations using an acid, acid-base and base modified vermiculite as a sustainable and recyclable adsorbent. Sci. Total Environ. 576, 398-408.

Steudel, A., 2008. Selection Strategy and Modification of Layer Silicates for Technical Applications. Univ.-Verlag Karlsruhe.

Steudel, A., Batenburg, L.F., Fischer, H.R., Weidler, P.G., Emmerich, K., 2009. Alteration of swelling clay minerals by acid activation. Appl. Clay Sci. 44, 105-115.

Stubičan, V., Roy, R., 1961. Infrared spectra of layer-structure silicates. J. Am. Ceram. Soc. 44, 625-627.

Stucki, J.W., 2006. Properties and behaviour of iron in clay minerals. In: Bergaya, F., Theng, B.K.G., Lagaly, G. (Eds.), Handbook of Clay Minerals. Elsevier.

Taylor, G.L., Routsala, A.P., 1968. Analysis of iron in layered silicates by Mossbauer spectroscopy. Clay Clay Miner. 16, 381-391.

Teng, T.T., Low, L.W., 2012. Removal of dyes and pigments from industrial effluents. In: Sharma, S.K., Sanghi, R. (Eds.), Advances in Water Treatment and Pollution Prevention. Springer, Netherlands.

Thommes, M., Kaneko, K., Neimark, A.V., Olivier, P., Rodriguez-Reinoso, F., Rouquerol, J., Sing, K.S.W., 2015. Physisorption of gases, with special reference to the evaluation of surface area and pore size distribution (IUPAC technical report). Pure Appl. Chem. 87, 1051-1069.

Tuček, J., Machala, L., Frydrych, J., Pechoušek, J., Zbořil, R., 2013. Mössbauer Spectroscopy in Study of Nanocrystalline Iron Oxides from Thermal Processes. Mössbauer Spectroscopy. John Wiley \& Sons, Inc., pp. 349-392.

Vandenberghe, E.R., Grave, E., 2006. Application of Mössbauer spectroscopy in earth sciences. In: Bergaya, F., Theng, B.K.G., Lagaly, G. (Eds.), Handbook of Clay Science. Elsevier Ltd.

Zhuravlev, L.T., 2000. The surface chemistry of amorphous silica. Zhuravlev model. Colloids Surf. A Physicochem. Eng. Asp. 173, 1-38. 